\title{
Clinical and laboratory features distinguishing pandemic H1N1 influenza-related pneumonia from interpandemic community-acquired pneumonia in adults
}

\author{
Thomas Bewick, ${ }^{1}$ Puja Myles, ${ }^{2}$ Sonia Greenwood, ${ }^{1}$ Jonathan S Nguyen-Van-Tam, ${ }^{2}$ \\ Stephen J Brett, ${ }^{3}$ Malcolm G Semple, ${ }^{4}$ Peter J Openshaw, ${ }^{5}$ Barbara Bannister, ${ }^{6}$ \\ Robert C Read, ${ }^{7}$ Bruce L Taylor, ${ }^{8}$ Jim McMenamin, ${ }^{9}$ Joanne E Enstone, ${ }^{2}$ \\ Karl G Nicholson, ${ }^{10}$ Wei Shen Lim, ${ }^{1}$ Influenza Clinical Information Network (FLU-CIN)
}

- Additional data are published online only. To view these files please visit the journal online (http://thorax.bmj.com)

${ }^{1}$ Department of Respiratory Medicine, Nottingham University Hospitals NHS Trust, Nottingham, UK ${ }^{2}$ Division of Epidemiology and Public Health, University of Nottingham, Nottingham, UK ${ }^{3}$ Centre for Peri-operative Medicine and Critical Care Research, Imperial College Healthcare NHS Trust, London, UK ${ }^{4}$ Department of Women's and Children's Health, University of Liverpool, Liverpool, UK

${ }^{5}$ Centre for Respiratory Infections, National Heart and Lung Institute, Imperial College, London, UK

${ }^{6}$ Department of Health, Skipton House, London, UK

${ }^{7}$ Department of Infection and Immunity, University of Sheffield, Royal Hallamshire Hospital, Sheffield, UK

${ }^{8}$ Department of Critical Care, Portsmouth Hospitals NHS Trust, Portsmouth, UK

${ }^{9}$ Health Protection Scotland, NHS National Services, Glasgow, UK ${ }^{10}$ Infectious Diseases Unit, University Hospitals of Leicester NHS Trust, Leicester Royal Infirmary, Leicester, UK

\section{Correspondence to}

Dr Wei Shen Lim, Respiratory Medicine, Nottingham University Hospitals NHS Trust, City Hospital Campus, Hucknall Road, Nottingham NG5 1PB, UK; weishen.lim@nuh.nhs.uk

Received 20 September 2010 Accepted 9 December 2010 Published Online First 20 January 2011

\section{UN IOCKED}

This paper is freely available online under the BMJ Journals unlocked scheme, see http:// thorax.bmi.com/site/about/ unlocked.xhtml

\section{ABSTRACT}

Background Early identification of patients with H1N1 influenza-related pneumonia is desirable for the early instigation of antiviral agents. A study was undertaken to investigate whether adults admitted to hospital with H1N1 influenza-related pneumonia could be distinguished clinically from patients with non-H1N1 community-acquired pneumonia (CAP).

Methods Between May 2009 and January 2010, clinical and epidemiological data of patients with confirmed H1N1 influenza infection admitted to 75 hospitals in the UK were collected by the Influenza Clinical Information Network (FLU-CIN). Adults with H1N1 influenza-related pneumonia were identified and compared with a prospective study cohort of adults with CAP hospitalised between September 2008 and June 2010, excluding those admitted during the period of the pandemic. Results Of 1046 adults with confirmed H1N1 influenza infection in the FLU-CIN cohort, 254 (25\%) had H1N1 influenza-related pneumonia on admission to hospital. In-hospital mortality of these patients was $11.4 \%$ compared with $14.0 \%$ in patients with inter-pandemic $\operatorname{CAP}(n=648)$. A multivariate logistic regression model was generated by assigning one point for each of five clinical criteria: age $\leq 65$ years, mental orientation, temperature $\geq 38^{\circ} \mathrm{C}$, leucocyte count $\leq 12 \times 10^{\circ} / \mathrm{l}$ and bilateral radiographic consolidation. A score of 4 or 5 predicted H1N1 influenza-related pneumonia with a positive likelihood ratio of 9.0. A score of 0 or 1 had a positive likelihood ratio of 75.7 for excluding it. Conclusion There are substantial clinical differences between H1N1 influenza-related pneumonia and inter-pandemic CAP. A model based on five simple clinical criteria enables the early identification of adults admitted with H1N1 influenza-related pneumonia.

\section{INTRODUCTION}

In March 2009 the first cases of a novel strain of influenza A virus of swine origin were reported in Mexico ${ }^{1}$ and, within 3 months, global spread led to declaration of a pandemic by the World Health Organization (WHO). While most cases of pandemic influenza H1N1 infection have been mild or subclinical, ${ }^{2-4}$ some patients experienced severe illness from H1N1 influenza infection and others severe influenza-related complications. ${ }^{5} 6$
Pneumonia is one of the commonest and most important complications of influenza infection. Influenza virus causes primary viral pneumonia, and secondary bacterial infections are also recognised. ${ }^{8}$ In contemporary cohorts of patients admitted with inter-pandemic community acquired pneumonia (CAP), influenza is frequently found as a co-pathogen alongside other respiratory pathogens such as Streptococcus pneumoniae. ${ }^{9-12}$ Studies of the 1918-19 influenza pandemic have suggested that the majority of influenza-related deaths during that period were caused by secondary bacterial pneumonia. ${ }^{13}$ More recently, in hospitalised patients with confirmed H1N1 influenza infection, radiological evidence of pneumonia was observed in $18-66 \%$ of patients. ${ }^{14-17}$ In addition, although not necessarily the cause of death, pneumonia was found in the majority of fatal cases at post-mortem examination. ${ }^{18} 19$ Overall, fewer than $30 \%$ of H1N1 influenza-related pneumonia cases have evidence of bacterial co-infection, ${ }^{20-22}$ suggesting that primary viral pneumonia is often important.

Early identification of patients with H1N1 influenza-related pneumonia may enable the early administration of antiviral agents with possible improved outcomes. ${ }^{23}$ However, there are few data relating to the clinical differentiation of H1N1 influenza-related pneumonia from inter-pandemic CAP. The aims of the current study were (1) to compare and contrast the clinical features of adult patients admitted with CAP versus H1N1 influenza-related pneumonia and (2) to develop a model that identifies H1N1 influenza-related pneumonia using simple clinical criteria.

\section{METHODS \\ Study patients \\ H1N1 influenza-related pneumonia cohort (H1N1 cohort)}

Between May 2009 and January 2010, the Influenza Clinical Information Network (FLU-CIN) collected clinical and epidemiological data on patients admitted to UK hospitals with confirmed H1N1 influenza infection. Seventy-five hospitals in 31 cities or towns were included. The details of data collection and the overall findings from the first wave of the 2009 pandemic have been described elsewhere. ${ }^{24} \mathrm{H} 1 \mathrm{~N} 1$ influenza infection 
was diagnosed by a positive polymerase chain reaction (PCR) result from respiratory samples obtained via a nasopharyngeal swab or bronchoalveolar lavage performed during the admission episode. Data collected included demography, clinical observations, clinical course, laboratory and radiological test results and outcome. The current study cohort comprised adults (aged $\geq 16$ years) whose admission chest $x$-rays met one of the following criteria:

1. Chest X-ray report clearly suggestive of pneumonia. ${ }^{25}$

2. Chest x-ray report showed acute infiltrates but no consolidation.

3. No chest $x$-ray report available but x-ray documented in the clinical notes as being in keeping with pneumonia $(n=24)$.

Patients who had acquired H1N1 influenza infection while in hospital or had been transferred to a study site from another hospital (eg, for extracorporeal membrane oxygenation therapy) were excluded.

\section{Non-H1N1 influenza CAP cohort (CAP cohort)}

Between September 2008 and June 2010, consecutive adult patients (aged $\geq 16$ years) admitted to a large UK teaching hospital trust (Nottingham University Hospitals NHS trust) with CAP were prospectively recruited as part of a populationbased observational cohort study. Patients were included if they had at least one acute symptom in keeping with a lower respiratory tract infection (breathlessness, cough, sputum production or fever), had new infiltrates on a chest x-ray and were treated by the admitting team for CAP. Patients were excluded if they had been admitted to hospital in the preceding 10 days, had tuberculosis, or had post-obstructive pneumonia due to lung cancer. Participants were identified by study investigators on a daily basis from the acute admitting medical wards and enrolled following informed consent. All patients were managed in a similar manner according to trust CAP guidelines at the discretion of the attending clinician. For the purposes of this analysis and to ensure inclusion of only cases without H1N1 influenza infection, participants were excluded if admitted during the period of H1N1 influenza circulation in Nottingham (between 30 April 2009 and 10 February 2010 - this interval comprising all cases of H1N1 influenza infection in the Nottingham area based on local Health Protection Agency data (unpublished)).

\section{Statistical methods}

Data were analysed using SPSS Version 16.0. Continuously distributed variables were compared between H1N1 and CAP cohorts using the Student's t test if data were normally distributed and the Mann-Whitney $U$ test if non-normally distributed. Categorical data were compared using Pearson $\chi^{2}$. In order to derive a clinical diagnostic model for H1N1 influenza-related pneumonia, continuously distributed variables were re-categorised into binary variables based on thresholds derived from established acute severity scores (CURB-65 score, ${ }^{26}$ Pneumonia Severity Index, ${ }^{27}$ Surviving Sepsis Campaign ${ }^{28}$ ) and univariate analysis using $\chi^{2}$ allowed calculation of odds ratios with $95 \%$ confidence intervals. Variables for inclusion in the final model were selected using automatic stepwise regression with both forwards (selection) and backwards (deletion) variants. The efficacy of the model for predicting H1N1 influenza-related pneumonia was then assessed by calculating the area under the curve (AUC) of the receiver-operating characteristic (ROC) curve.

\section{RESULTS}

\section{Patient characteristics}

Of 1046 adults with confirmed H1N1 influenza infection in the FLU-CIN cohort, 266 (25.4\%) had evidence of either radiographic consolidation or other infiltrates consistent with acute infection. Twelve patients were transferred in from hospitals outside the study area or developed influenza infection while already an inpatient, leaving a study cohort of 254 patients (H1N1 cohort). The comparator group comprised 648 patients with interpandemic CAP (CAP cohort). The patient characteristics are summarised in table 1 and the relative age distribution of both cohorts is shown in figure 1 . Despite having similar in-hospital mortality (H1N1 cohort $11.4 \%$; CAP cohort $14.0 \%$ ), the two groups differed substantially. The median age of patients in the $\mathrm{H} 1 \mathrm{~N} 1$ cohort was 42 years compared with 75 years in the CAP cohort $(p<0.001)$. The most common comorbid illnesses in the $\mathrm{H} 1 \mathrm{~N} 1$ cohort were asthma (25.2\%) and diabetes mellitus $(9.8 \%)$ compared with chronic obstructive pulmonary disease (COPD) $(26.1 \%)$ and diabetes mellitus $(15.4 \%)$ in the CAP cohort. In the H1N1 cohort, $9.4 \%$ of patients had $\geq 3$ comorbid illnesses compared with $11.9 \%$ of controls. In addition, patients in the H1N1 cohort were more likely to be febrile, tachycardic, have bilateral radiographic abnormalities and have lower leucocyte counts and levels of C-reactive protein. Confusion, comorbidity and blood urea levels were higher among patients in the CAP cohort. Within the H1N1 cohort, 11 (4.3\%) were pregnant and 21 (8.3\%) were obese. The value of the CURB-65 score in predicting inpatient mortality was assessed by calculating the AUC for ROC curves for each group; the AUC for the H1N1 cohort was 0.650 compared with 0.741 for the CAP cohort.

\section{Derivation of a clinical model for the diagnosis of H1N1 influenza-related pneumonia}

Nine categorical variables were found to be associated with H1N1 influenza-related pneumonia on univariate analysis (table 2). Two of these variables (C-reactive protein and albumin) were excluded from the derivation of the diagnostic prediction model because they are not routinely performed on admission in all hospitals for acutely ill patients. In a logistic regression model, five of the seven variables were found to be statistically significant at the $5 \%$ level (table 3 ). These variables remained statistically significant using both forwards and backwards stepwise regression models. The resulting 5-point score generated a ROC curve AUC of 0.873 (based on 858 data points). The derived score stratifies patients into three risk groups for $\mathrm{H} 1 \mathrm{~N} 1$ influenza-related pneumonia as shown in table 4. In order to assess the impact of age on the discriminant model, a further analysis was undertaken with age excluded from the logistic regression analysis, leaving the four variables of bilateral radiographic consolidation, mental orientation, leucocyte count $\leq 12 \times 10^{9} / 1$ and temperature $\geq 38^{\circ} \mathrm{C}$. The resulting ORs were 3.0 (95\% CI 2.0 to 4.4), 6.3 (95\% CI 3.5 to 11.5), 9.4 (95\% CI 6.3 to 14.3 ) and 2.6 (95\% CI 1.8 to 3.8 ), respectively. The ROC curve AUC for this model was 0.806 . Use of age $\leq 65$ years as a single binary predictor gave an AUC of 0.794 .

C-reactive protein and albumin were excluded from the initial logistic regression analysis in order to maximise clinical utility of the algorithm. When both variables were included as part of a multivariate analysis for exploratory purposes (H1N1 cohort, $\mathrm{n}=123$; CAP cohort, $\mathrm{n}=456$ ), only albumin $\leq 30 \mathrm{~g} / \mathrm{dl}$ was statistically significant at the 5\% level (OR 1.9; 95\% CI 1.1 to 3.5). The five previously described variables of age $\leq 65$ years, bilateral radiographic consolidation, mental orientation, leucocyte count $\leq 12 \times 10^{9} / 1$ and temperature $\geq 38^{\circ} \mathrm{C}$ remained statistically significant within the model.

As the age profiles of the two cohorts were significantly different and age may be a surrogate for other confounding factors, a secondary analysis was undertaken including only 
Table 1 Clinical characteristics of patients with H1N1 influenza-related pneumonia compared with community-acquired pneumonia (CAP)

\begin{tabular}{|c|c|c|c|}
\hline Characteristic & H1N1 cohort $(n=254)$ & CAP cohort $(n=648)$ & p Value \\
\hline \multicolumn{4}{|l|}{ Demographics } \\
\hline Age (years) & $42(29-54)$ & $75(61-84)$ & $<0.001$ \\
\hline Male & $109(42.9 \%)$ & $367(56.6 \%)$ & $<0.001$ \\
\hline \multicolumn{4}{|l|}{ Admission observations } \\
\hline Temperature $\left({ }^{\circ} \mathrm{C}\right)$, mean $(95 \% \mathrm{Cl})$ & $38.1(37.9$ to 38.2$)(n=245)$ & $37.5(37.4$ to 37.6$)(n=644)$ & $<0.001$ \\
\hline Pulse (/min) & $110(97-120)(n=244)$ & $100(86-115)(n=646)$ & $<0.001$ \\
\hline $\mathrm{SBP}(\mathrm{mm} \mathrm{Hg})$, mean $(95 \% \mathrm{Cl})$ & $125(123$ to 128$)(n=243)$ & $126(124$ to 129$)(n=646)$ & 0.61 \\
\hline Respiratory rate (/min) & $24(19-28)(n=240)$ & $22(18-28)(n=646)$ & 0.14 \\
\hline Confusion & $18(7.1 \%)$ & $182(28.1 \%)$ & $<0.001$ \\
\hline \multicolumn{4}{|l|}{ Outcome } \\
\hline Critical care admission & $88(34.6 \%)$ & $83(12.8 \%)$ & $<0.001$ \\
\hline LOS for survivors (days) & $6(3-11)(n=206)$ & $8(4-14)(n=553)$ & 0.003 \\
\hline Inpatient death & $29(11.4 \%)$ & $91(14.0 \%)$ & 0.296 \\
\hline \multicolumn{4}{|l|}{ Investigations } \\
\hline Bilateral consolidation & $89(39.0 \%$ of 228$)$ & $129(19.9 \%)$ & $<0.001$ \\
\hline White cell count $\left(\times 10^{9} / I\right)$ & $7.6(5.4-11.3)(n=239)$ & $14.5(10.5-19.9)(n=646)$ & $<0.001$ \\
\hline Urea $(\mathrm{mmol} / \mathrm{l})$ & $4.7(3.3-6.9)(n=232)$ & $7.9(5.5-12.6)(n=647)$ & $<0.001$ \\
\hline C-reactive protein (mg/l) & $85(34-199)(n=184)$ & $148(61-248)(n=602)$ & $<0.001$ \\
\hline Albumin $(g / d l)$ & $34(30-40)(n=177)$ & $31(27-35)(n=488)$ & $<0.001$ \\
\hline \multicolumn{4}{|l|}{ Symptoms } \\
\hline Productive cough & $147(57.9 \%)$ & $287(58.7 \%$ of $489 *)$ & 0.83 \\
\hline Dyspnoea & $151(59.4 \%)$ & $428(87.5 \%$ of $489 *)$ & $<0.001$ \\
\hline \multicolumn{4}{|l|}{ Comorbidity } \\
\hline Asthma & $64(25.2 \%)$ & $57(8.8 \%)$ & $<0.001$ \\
\hline COPD & $24(9.4 \%)$ & $169(26.1 \%)$ & $<0.001$ \\
\hline CCF & $1(0.4 \%)$ & $46(7.1 \%)$ & $<0.001$ \\
\hline Diabetes mellitus & $25(9.8 \%)$ & $100(15.4 \%)$ & 0.029 \\
\hline Charlson index, mean $(95 \% \mathrm{CI})$ & $1.11(0.94$ to 1.27$)$ & 1.33 (1.23 to 1.44$)$ & 0.023 \\
\hline
\end{tabular}

those patients aged $<65$ years (H1N1 cohort, $n=228$; CAP cohort, $\mathrm{n}=200$ ). Within this subgroup, median age remained significantly different (39years vs 50 years; $p<0.001$ ). In a logistic regression analysis, leucocyte count $\leq 12 \times 10^{9} / 1$ (OR $10.1,95 \%$ CI 6.1 to 16.7 ), age $\leq 50$ years (OR $2.7,95 \%$ CI 1.6 to 4.4 ), bilateral radiographic change (OR $2.5,95 \%$ CI 1.5 to 4.4 )

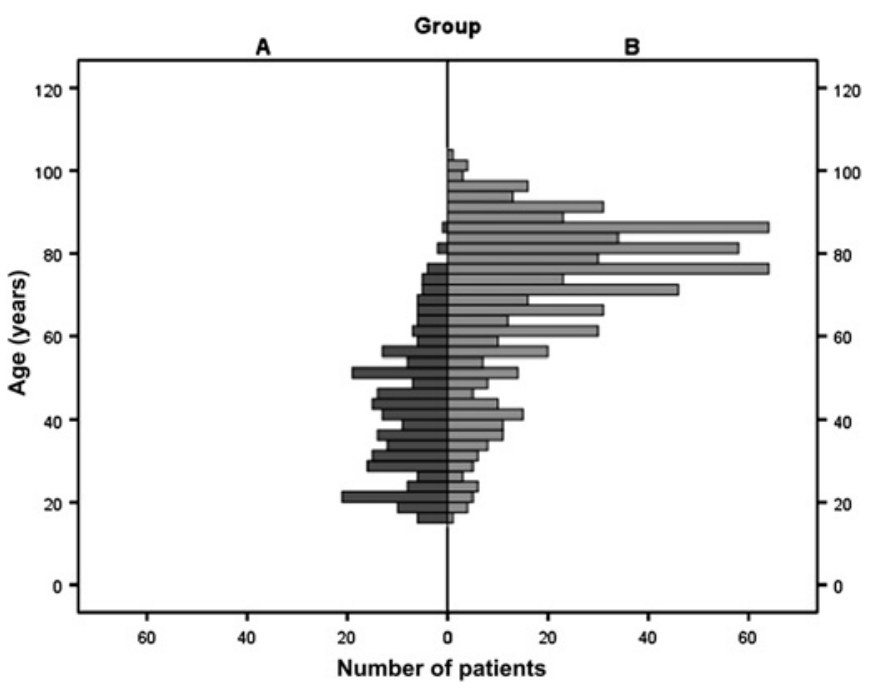

Figure 1 Age distribution of patients with H1N1 influenza-related pneumonia (group A) compared with community-acquired pneumonia (group B). and temperature $\geq 38^{\circ} \mathrm{C}$ (OR 2.1, 95\% CI 1.3 to 3.4 ) were the only significant contributors to the final model. Using this model to predict $\mathrm{H} 1 \mathrm{~N} 1$ influenza-related pneumonia, the AUC for the ROC curve was 0.789 .

A model to distinguish $\mathrm{H} 1 \mathrm{~N} 1$ influenza-related pneumonia based solely on physiological and radiological variables available rapidly in the emergency department (ie, excluding laboratory results) is shown in the online supplement.

\section{DISCUSSION}

To our knowledge, this is the first study to highlight the clinical differences between inter-pandemic CAP and H1N1

Table 2 Univariate association between selected clinical characteristics and presence of H1N1 infection

\begin{tabular}{llllll}
\hline Characteristic & $\begin{array}{l}\text { H1N1 } \\
\text { cohort }\end{array}$ & $\begin{array}{l}\text { CAP } \\
\text { cohort }\end{array}$ & OR & 95\% Cl & p Value \\
\hline Age $\leq 65$ years & $228 / 254$ & $200 / 648$ & 19.6 & 12.7 to 30.3 & $<0.001$ \\
White cell count $\leq 12 \times 10^{9} / \mathrm{l}$ & $189 / 239$ & $222 / 646$ & 7.2 & 5.1 to 10.3 & $<0.001$ \\
Oriented in time/place/person & $236 / 254$ & $466 / 648$ & 5.1 & 3.1 to 8.5 & $<0.001$ \\
Urea $<7 \mathrm{mmol} / \mathrm{l}$ & $175 / 232$ & $270 / 647$ & 4.3 & 3.1 to 6.0 & $<0.001$ \\
Temperature $\geq 38^{\circ} \mathrm{C}$ & $142 / 245$ & $232 / 644$ & 2.5 & 1.8 to 3.3 & $<0.001$ \\
Bilateral $\mathrm{x}$-ray change & $89 / 228$ & $129 / 648$ & 2.6 & 1.9 to 3.6 & $<0.001$ \\
CRP $\leq 50 \mathrm{mg} / \mathrm{l}$ & $67 / 184$ & $126 / 602$ & 2.2 & 1.5 to 3.1 & $<0.001$ \\
Albumin $\leq 30 \mathrm{~g} / \mathrm{dl}$ & $44 / 177$ & $189 / 488$ & 1.9 & 1.3 to 2.8 & 0.001 \\
Female sex & $145 / 254$ & $281 / 648$ & 1.7 & 1.3 to 2.3 & 0.001 \\
Pulse $\geq 125 / \mathrm{min}$ & $45 / 244$ & $107 / 646$ & 1.1 & 0.8 to 1.7 & 0.51 \\
\hline
\end{tabular}

$\mathrm{CAP}$, community-acquired pneumonia; CRP, C-reactive protein. 
Table 3 Multivariate analysis of variables associated with H1N1 influenza-related pneumonia

\begin{tabular}{lclc}
\hline Characteristic & 0dds ratio & 95\% Cl & p Value \\
\hline Age $\leq 65$ years & 12.7 & 7.2 to 22.2 & $<0.001$ \\
White cell count $\leq 12 \times 10^{9} / \mathrm{I}$ & 9.7 & 6.1 to 15.6 & $<0.001$ \\
Bilateral radiographic change & 3.3 & 2.1 to 5.4 & $<0.001$ \\
Oriented in time/place/person & 2.6 & 1.2 to 5.3 & 0.012 \\
Temperature $\geq 38^{\circ} \mathrm{C}$ & 1.9 & 1.3 to 3.0 & 0.003 \\
Female sex & 1.4 & 0.9 to 2.2 & 0.09 \\
Urea $<7 \mathrm{mmol} / \mathrm{l}$ & 1.4 & 0.8 to 2.3 & 0.214
\end{tabular}

Complete data on all seven variables were available in 205 patients in the H1N1 cohort and 642 patients in the community-acquired pneumonia cohort.

influenza-related pneumonia. Patients with H1N1 influenzarelated pneumonia were significantly younger than patients with CAP, reflecting the epidemiology of $\mathrm{H} 1 \mathrm{~N} 1$ influenza infection globally. ${ }^{2} 14242930$ This may relate to previous exposure of older persons to pre-2009 H1N1 influenza viruses conferring some immunity. ${ }^{31-33}$ In future years, as the virus evolves, the epidemiology of H1N1 infection may alter to affect older persons to a greater extent. Such a shift would also impact on the age distribution of patients developing H1N1 influenzarelated pneumonia with potentially important consequences on resultant morbidity and mortality. Studies of CAP conducted in inter-pandemic years demonstrate an association between extremes of age or frailty and influenza or viral infection. ${ }^{10} 11$

Lower levels of C-reactive protein and leucocytes were observed in patients with H1N1 influenza-related pneumonia. This finding is consistent with reports from studies of interpandemic influenza-related pneumonia of relatively low leucocyte, neutrophil and C-reactive protein levels. ${ }^{10-12}$ These markers of inflammation are driven mainly by bacterial infections, and the predominance of primary viral pneumonia as opposed to secondary bacterial pneumonia in H1N1 influenzarelated pneumonia may therefore partially account for this observation. ${ }^{16}{ }^{34}$ Despite the lower levels of C-reactive protein and leucocytes, patients with H1N1 influenza-related pneumonia had higher levels of fever than patients with CAP. This may be related to high levels of production of proinflammatory cytokines, particularly interleukin $6,{ }^{35}$ with reduced innate and adaptive responses to $S$ pneumoniae seen with pandemic H1N1 influenza. ${ }^{36}$ It may also partially reflect the relative inability of older subjects to mount a febrile response to serious infection. ${ }^{37}$

A diagnostic prediction model was derived from five simple clinical criteria-age $\leq 65$ years, presence of bilateral radiographic consolidation, absence of confusion as measured by orientation in time, place or person, leucocyte count $\leq 12 \times 10^{9} / 1$ and temperature $\geq 38^{\circ} \mathrm{C}$. Assigning one point for each clinical criterion present, a score of 4 or 5 gave a positive likelihood ratio of 9.0 for predicting $\mathrm{H} 1 \mathrm{~N} 1$ influenza-related pneumonia, while a score of 0 or 1 gave a positive likelihood ratio of 75.7 for excluding H1N1 influenza-related pneumonia. Although age is by far the single strongest predictor (OR 19.6), its predictive value is inferior to the proposed model comprising five variables. When age was removed from the proposed model, the remaining four variables-bilateral radiographic consolidation, mental orientation, leucocyte count $\leq 12 \times 10^{9} / 1$ and temperature $\geq 38^{\circ} \mathrm{C}$-retained their significance as independent predictors of
H1N1 influenza-related pneumonia, attesting to their importance within the model. This model is applicable at the time of admission when a diagnosis of CAP is determined and would be useful in aiding the early diagnosis of patients with H1N1 influenza-related pneumonia as well as management decisions relating to infection control and the instigation of early empirical antiviral therapy. Although the efficacy of antiviral agents in the treatment of patients hospitalised with influenza-related pneumonia is not scientifically proven, ${ }^{38}$ evidence from observational studies in hospital settings suggests that early antiviral use does improve clinical outcomes. ${ }^{14} 233940$

Currently, this diagnostic prediction model can only be advocated for H1N1 influenza-related pneumonia. It should not be applied to other viral pneumonias without further validation. Similarly, should pandemic influenza A/H1N1 2009 evolve and affect older persons more widely, the predictive value of the model is likely to be altered.

Disease severity assessment is crucial in the management of patients with pneumonia. The CURB-65 severity assessment score has been validated for use in predicting 30-day mortality in patients with $\mathrm{CAP}^{26}$ and was advocated as potentially useful in patients with influenza-related pneumonia. ${ }^{41} 42$ However, this study suggests that, in patients with $\mathrm{H} 1 \mathrm{~N} 1$ influenza-related pneumonia, the CURB-65 score does not perform so well. This difference may be due to a combination of features including the lower age distribution and comorbidity profile of patients with H1N1 influenza-related pneumonia and differences in the inflammatory response to $\mathrm{H} 1 \mathrm{~N} 1$ influenza infection. ${ }^{43}$ Further study of the prognostic factors relevant to H1N1 influenza-related pneumonia is warranted.

\section{Study limitations}

The main limitation to this study is that the CAP cohort was not collected contemporaneously with the H1N1 cohort and, while the latter patients were distributed nationally, patients in the CAP cohort were recruited from a single study centre. Patients in the CAP cohort were prospectively enrolled as part of a population-based cohort study involving all patients hospitalised with CAP in the Nottingham area (catchment population 750000). Nottingham has a record of conducting large cohort studies of CAP. ${ }^{44-47}$ The age and demographics of this CAP study cohort mirror the demographics of patients with CAP described in a recently completed national multicentre audit of CAP organised by the British Thoracic Society (unpublished data). These factors support the view that the CAP cohort is representative of patients admitted to hospital with CAP.

Patients recruited to the FLU-CIN cohort were identified following testing for H1N1 influenza on the basis of clinical suspicion rather than rigorously applied testing criteria. Nevertheless, the FLU-CIN cohort is similar to other large published $\mathrm{H} 1 \mathrm{~N} 1$ influenza cohorts in terms of clinical features and rates of pneumonia (22-37\%) and critical care admission $(13-25 \%){ }^{14} 48 \quad 49 \quad 17$ These observations suggest that the FLU-CIN cohort is indeed representative of patients hospitalised with H1N1 infection in the UK and is not biased in relation to patients with influenza-related pneumonia or patients with severe disease.

Table 4 Proportions of patients identified with H1N1 influenza-related pneumonia according to the diagnostic prediction model

\begin{tabular}{lllllll}
\hline Score $^{*}$ & $\mathbf{0}$ & $\mathbf{1}$ & $\mathbf{2}$ & $\mathbf{3}$ & $\mathbf{4}$ & $\mathbf{5}$ \\
\hline Proportion with H1N1 pneumonia & $0 / 55(0 \%)$ & $1 / 171(0.6 \%)$ & $24 / 250(9.6 \%)$ & $65 / 214(30.3 \%)$ & $95 / 133(71.4 \%)$ & $31 / 35(88.6 \%)$ \\
\hline
\end{tabular}

${ }^{*}$ One point for the presence of each of: age $\leq 65$ years, white cell count $\leq 12 \times 10^{9} / \mathrm{l}$, bilateral radiographic change, oriented in time/place/person and temperature $\geq 38^{\circ} \mathrm{C}$. 
All patients with H1N1 influenza-related pneumonia had laboratory-confirmed pandemic H1N1 influenza infection so misclassification is eliminated. In contrast, it remains possible that the CAP cohort may have contained patients in whom the precipitating cause of pneumonia was influenza, despite the exclusion of patients admitted with CAP during the period when pandemic H1N1 influenza was circulating in the study catchment population. The inclusion of some individuals with influenza-related pneumonia within the CAP cohort would tend towards increasing the similarities between the two groups thereby producing underestimates of any differences.

\section{CONCLUSIONS}

H1N1 influenza-related pneumonia differs substantially from inter-pandemic CAP. A diagnostic prediction model based on the five clinical features of age ( $\leq 65$ years), leucocyte count $\left(\leq 12 \times 10^{9} / 1\right)$, bilateral radiographic change, temperature $\left(\geq 38^{\circ} \mathrm{C}\right)$ and mental orientation (time/person/place) allows the early discrimination of H1N1 influenza-related pneumonia from CAP following hospital admission and confers confidence to the instigation of early empirical antiviral therapy.

Acknowledgements The authors thank Elaine Gadd and Colin Armstrong, Department of Health, England for their invaluable contribution in relation to the FLUCIN programme and also gratefully acknowledge individuals who helped identify cases and collated clinical data: Alison Booth, Margaret Charlesworth, Sarah Rodenhurst, Angela Ballard and Alison Holmes at Imperial College Healthcare NHS Trust, London, UK; Sally Batham, Phayre Parkinson, Tracy Kumar and Aiden Dunphy at the University Hospitals of Leicester NHS Trust, Leicester, UK; Anne Tunbridge, Patty Hempsall, Joyce Linskill, Aimee Turner, Sharon Grindle, Dawn Shelvin and Eric Moulds at Sheffield University Hospitals NHS Trust, Sheffield, UK; Elvina White, Elaine Scott, Jennifer Cater, Erica Sergi and Helen Hill at Alder Hey Children's Hospital NHS Foundation Trust, Liverpool, UK; Deborah Fleetwood, Lorna Roche, Sarah Dyas and Maria Boswell at the Royal Liverpool and Broadgreen University Hospital's Trust, Liverpool, UK; Gillian Vernon, Gillian Houghton, Heather Longworth and Angela Kerrigan at Liverpool Women's Hospital, Liverpool, UK; Gemma Thompson, Emily Jarvis and Charlotte Minter at the Nottingham University Hospitals NHS Trust, Nottingham, UK; Kristina Lum Kin, Jacqueline Daglish, Sam Hayton and Gemma Slinn at Birmingham Children's Hospital, Birmingham, UK; Michelle Lacey and Ali McAllister at Quality Improvement Scotland; Karen Duffy, Anne Gordon and Kevin Rooney at Greater Glasgow and Clyde NHS Hospitals, colleagues in Scotland who contributed to the FLU-CIN data - Eleanor Anderson, Malcolm McWhirter, Hilary Davison, William Carmen, Alastair MacConnachie, Mark Cotton, Arlene Reynolds, Heather Murdoch, Karen Voy and Rosie Hague; Brian Smyth and Cathriona Kearns from the National Public Health Agency, Northern Ireland for identifying cases and facilitating data collection; Teresa Cunningham at the Southern Trust and Leslie Boydell at the Belfast Trust for facilitating data collection; Alemayehu Amberbir, Safaa Al-Badri, Baraa Mahgoob and Nachi Arunachalam at the University of Nottingham for data entry and obtaining background population data; also Graham Watson for database development and support. The authors also thank Sir Gordon Duff, Co-Chair of the Scientific Advisory Group for Emergencies, and Janet Darbyshire, Co-Chair of the Influenza Clinical Information Network Strategy Group, for their support; Shona Kelly of the University of Nottingham for help in developing the initial FLU-CIN data collection tool; and Patrick O'Brien of University College London Hospitals NHS Foundation Trust for assistance in further developing the data set. They thank those Chief Executive Officers, clinicians, virologists and managers too numerous to mention who were active in notifying cases to FLU-CIN. SJB and PJMO wish to acknowledge the support of the UK NIHR Biomedical Research Centre scheme.

Funding The Department of Health in England was the main funder for FLU-CIN Chairmanship of the FLU-CIN Strategy Group (that includes JSN-V-T, WSL, MGS, PJMO, RCR, BLT, SJB, JMcM, JEE and KGN as members) was provided by the Department of Health, England. The FLU-CIN Strategy Group had final responsibility for the interpretation of findings and decision to submit for publication. The CAP cohort study was funded by an unrestricted educational grant from Wyeth (now Pfizer).

Competing interests JSN-V-T has received funding to attend influenza related meetings, lecture and consultancy fees and research funding from several influenza antiviral drug and vaccine manufacturers and is a former employee of SmithKline Beecham plc (now GlaxoSmithKline), Roche Products Ltd and Sanofi-Pasteur MSD. SJB has received consultancy fees from GlaxoSmithKline and Baxter. MGS and BB are advisors to the Department of Health, England. PJMO is a member of the European Scientific Working Group on Influenza (ESWI) which is funded by the pharmaceutical industry. JEE has received consultancy fees from GlaxoSmithKline and performed paid work for the Department of Health, England. KGN has received H5 avian influenza vaccines from Novartis and H1N1 pandemic influenza vaccines from GlaxoSmithKline and Baxter to facilitate MRC and NIHR-funded trials. He has received consultancy fees from Novartis and GlaxoSmithKline and lecture fees from Baxter. A colleague of KGN at the University Hospitals of Leicester NHS Trust was Principal Investigator and recipient of research funding from Roche on antiviral resistance and from Novartis on pandemic H1N1 vaccines. WSL has received an unrestricted educational grant from Wyeth (now Pfizer).

Ethics approval Before commencement, FLU-CIN procedures were reviewed by the Ethics and Confidentiality Committee of the National Information Governance Board for Health and Social Care in England and approved for collection, storage and use of personal data for surveillance purposes. Full ethical approval was obtained from the Nottingham Research Ethics Committee for the conduct of the CAP cohort study.

Contributors All authors were involved with designing the study, interpreting and analysing the data and contributed to the report and approved the final version. JEE trained FLU-CIN data collectors, coordinated data collection, collated the data and oversaw data entry with JSN-V-T and PM. SG collected data for FLU-CIN and the CAP cohort. TB and PM analysed the data. TB and WSL wrote the report with assistance from all co-authors and are guarantors. The findings and conclusions in this report are those of the authors and do not necessarily represent the official position of their respective employers.

Provenance and peer review Not commissioned; externally peer reviewed.

\section{REFERENCES}

1. Center for Disease Control (CDC). Outbreak of swine-origin influenza $A(H 1 N 1)$ virus infection - Mexico, March-April 2009. MMWR Morb Mortal Wkly Rep 2009;58:467-70.

2. Gilsdorf A, Poggensee $\mathrm{G}$, on behalf of the working group pandemic influenza A(H1N1)v. Influenza A(H1N1)v in Germany: the first 10,000 cases. Euro Surveill. 2009:14(34)1-4. Available online: http://www.eurosurveillance.org/ViewArticle. aspx?Articleld $=19318$.

3. Dawood FS, Jain S, Finelli L, et al; Novel Swine-Origin Influenza A(H1N1) Investigation Team. Emergence of a novel swine-origin influenza $A(H 1 N 1)$ virus in humans. N Engl J Med 2009;360:2605-15.

4. Miller E, Hoschler K, Hardelid P, et al. Incidence of 2009 pandemic influenza A H1N1 infection in England: a cross-sectional serological study. Lancet 2010:375:1100-8.

5. ANZIC Influenza Investigators, Webb SAR, Pettilä V, et al. Critical care services and 2009 H1N1 influenza in Australia and New Zealand. N Engl J Med 2009;361:1925-34.

6. Kumar A, Zarychanski R, Pinto R, et al. Critically ill patients with 2009 influenza A(H1N1) infection in Canada. JAMA 2009:302:1872-9.

7. Rothberg MB, Haessler SD, Brown RB. Complications of viral influenza. Am J Med 2008;121:258-64.

8. Klugman KP, Chien YW, Madhi SA. Pneumococcal pneumonia and influenza: a deadly combination. Vaccine 2009:27(Suppl 3):C9-14.

9. Templeton KE, Scheltinga SA, van den Eeden WCJFM, et al. Improved diagnosis of the etiology of community-acquired pneumonia with real-time polymerase chain reaction. Clin Infect Dis 2005; $\mathbf{4 1 : 3 4 5 - 5 1 . ~}$

10. Jennings LC, Anderson TP, Beynon KA, et al. Incidence and characteristics of vira community-acquired pneumonia in adults. Thorax 2008:63:42-8.

11. Johnstone J, Majumdar SR, Fox JD, et al. Viral infection in adults hospitalized with community-acquired pneumonia: prevalence, pathogens, and presentation. Chest 2008:134:1141-8.

12. Marcos MA, Camps M, Pumarola T, et al. The role of viruses in the aetiology of community-acquired pneumonia in adults. Antivir Ther 2006:11:351-9.

13. Morens DM, Taubenberger JK, Fauci AS. Predominant role of bacterial pneumonia as a cause of death in pandemic influenza: implications for pandemic influenza preparedness. J Infect Dis 2008;198:962-70.

14. Jain S, Kamimoto L, Bramley AM, et al. Hospitalized patients with 2009 H1N1 influenza in the United States, April-June 2009. N Engl J Med 2009;361:1935-44.

15. Perez-Padilla R, de la Rosa-Zamboni D, de Leon SP, et al. Pneumonia and respiratory failure from swine-origin influenza $\mathrm{A}(\mathrm{H} 1 \mathrm{N1})$ in Mexico. N Engl J Med 2009;361:680-9.

16. Louie JK, Acosta M, Winter K, et al. Factors associated with death or hospitalization due to pandemic 2009 influenza $A(H 1 N 1)$ infection in California. JAMA 2009:302:1896-902.

17. Mu Y, Zhang Z, Chen X, et al. Clinical features, treatments and prognosis of the initial cases of pandemic influenza H1N1 2009 virus infection in Shanghai China. OJM 2010:103:311-17.

18. Gill JR, Sheng ZM, Ely SF, et al. Pulmonary pathologic findings of fatal 2009 pandemic influenza A/H1N1 viral infections. Arch Pathol Lab Med 2010;134:235-43.

19. Harms PW, Schmidt LA, Smith LB, et al. Autopsy findings in eight patients with fatal H1N1 influenza. Am J Clin Pathol 2010;134:27-35

20. Centers for Disease Control (CDC). Bacterial coinfections in lung tissue specimens from fatal cases of 2009 pandemic influenza A(H1N1) - United States, May-August 2009. MMWR Morb Mortal Wkly Rep 2009;58:1071-4. 
21. Rello J, Rodríguez $\mathrm{A}$, Ibañez $\mathrm{P}$, et al. Intensive care adult patients with severe respiratory failure caused by influenza A(H1N1)v in Spain. Crit Care 2009;13:R148

22. Riquelme R, Riquelme M, Rioseco ML, et al. Characteristics of hospitalized patients with 2009 H1N1 influenza in Chile. Eur Respir J 2010:36:864-9.

23. Bautista E, Chotpitayasunondh T, Gao Z, et al; of the WHO Consultation on Clinical Aspects of Pandemic (H1N1) 2009 Influenza WC. Clinical aspects of pandemic 2009 influenza A(H1N1) virus infection. N Engl J Med 2010;362:1708-19.

24. Nguyen-Van-Tam JS, Openshaw PJM, Hashim A, et al. Risk factors for hospitalisation and poor outcome with pandemic A/H1N1 influenza: United Kingdom first wave (May-September 2009). Thorax 2010;65:645-51.

25. Franquet T. Imaging of pneumonia: trends and algorithms. Eur Respir $J$ 2001:18:196-208

26. Lim WS, van der Eerden MM, Laing R, et al. Defining community acquired pneumonia severity on presentation to hospital: an international derivation and validation study. Thorax 2003;58:377-82.

27. Fine MJ, Auble TE, Yealy DM, et al. A prediction rule to identify low-risk patients with community-acquired pneumonia. N Engl J Med 1997;336:243-50.

28. Dellinger RP, Levy MM, Carlet JM, et al. Surviving Sepsis Campaign: international guidelines for management of severe sepsis and septic shock. Intensive Care Med 2008:34:17-60.

29. Echevarría-Zuno S, Mejía-Aranguré JM, Mar-Obeso AJ, et al. Infection and death from influenza A H1N1 virus in Mexico: a retrospective analysis. Lancet 2009:374:2072-9.

30. Cao B, Li XW, Mao Y, et al. Clinical features of the initial cases of 2009 pandemic influenza A(H1N1) virus infection in China. N Engl J Med 2009;361:2507-17.

31. Hancock K, Veguilla V, Lu X, et al. Cross-reactive antibody responses to the 2009 pandemic H1N1 influenza virus. N Engl J Med 2009;361:1945-52.

32. Ross TM, Mahmood K, Crevar CJ, et al. A trivalent virus-like particle vaccine elicits protective immune responses against seasonal influenza strains in mice and ferrets. PLoS One 2009; 4:e6032.

33. Skountzou I, Koutsonanos DG, Kim JH, et al. Immunity to pre-1950 H1N1 influenza viruses confers cross-protection against the pandemic swine-origin $2009 \mathrm{~A}(\mathrm{H} 1 \mathrm{~N} 1)$ influenza virus. J Immunol 2010;185:1642-9.

34. Shieh WJ, Blau DM, Denison AM, et al. 2009 pandemic influenza A(H1N1): pathology and pathogenesis of 100 fatal cases in the United States. Am J Pathol 2010;177:166-75.

35. Lee $\mathbf{N}$, Wong CK, Chan PKS, et al. Hypercytokinemia and hyperactivation of phospho-p38 mitogen-activated protein kinase in severe human influenza $A$ virus infection. Clin Infect Dis 2007:45:723-31.
36. Giamarellos-Bourboulis EJ, Raftogiannis M, Antonopoulou A, et al. Effect of the novel influenza $A(\mathrm{H} 1 \mathrm{~N} 1)$ virus in the human immune system. PLoS One 2009:4:e8393.

37. High KP, Bradley SF, Gravenstein S, et al. Clinical practice guideline for the evaluation of fever and infection in older adult residents of long-term care facilities: 2008 update by the Infectious Diseases Society of America. Clin Infect Dis 2009;48:149-71

38. Reddy D. Responding to pandemic (H1N1) 2009 influenza: the role of oseltamivir. $J$ Antimicrob Chemother 2010:65(Suppl 2):ii35-40.

39. Lee N, Choi KW, Chan PKS, et al. Outcomes of adults hospitalised with severe influenza. Thorax 2010;65:510-15.

40. Hanshaoworakul W, Simmerman JM, Narueponjirakul U, et al. Severe human influenza infections in Thailand: oseltamivir treatment and risk factors for fatal outcome. PLoS One 2009; 4:e6051.

41. Lim WS, Baudouin SV, George RC, et al. BTS guidelines for the management of community acquired pneumonia in adults: update 2009. Thorax 2009;64(Suppl3): iii1-55.

42. Mandell LA, Wunderink RG, Anzueto A, et al. Infectious Diseases Society of America/American Thoracic Society consensus guidelines on the management of community-acquired pneumonia in adults. Clin Infect Dis 2007:44(Suppl 2): S27-72.

43. Woo PCY, Tung ETK, Chan KH, et al. Cytokine profiles induced by the novel swine-origin influenza A/H1N1 virus: implications for treatment strategies. J Infect Dis 2010;201:346-53

44. Macfarlane JT, Finch RG, Ward MJ, Macrae AD. Hospital study of adult community-acquired pneumonia. Lancet 1982:2:255-8.

45. Woodhead MA, Macfarlane JT, McCracken JS, et al. Prospective study of the aetiology and outcome of pneumonia in the community. Lancet 1987:1:671-4.

46. Lim WS, Macfarlane JT, Boswell TC, et al. Study of community acquired pneumonia aetiology (SCAPA) in adults admitted to hospital: implications for management guidelines. Thorax 2001:56:296-301.

47. Bewick T, Cooper VJ, Lim WS. Does early review by a respiratory physician lead to a shorter length of stay for patients with non-severe community-acquired pneumonia? Thorax 2009;64:709-12.

48. Bishop JF, Murnane MP, Owen R. Australia's winter with the 2009 pandemic influenza $\mathrm{A}(\mathrm{H} 1 \mathrm{N1})$ virus. N Engl J Med 2009;361:2591-4.

49. Semionov A, Tremblay C, Samson L, et al. Pandemic influenza A(H1N1) 2009: chest radiographic findings from 147 proven cases in the Montreal area. Can Assoc Radiol J 2010:61:233-40.

\section{Thorax Online Archive}

Visit our Online Archive - available back to 1946. Subscribers may access the entire archive freely. Non-subscribers have free access to all articles prior to 2006. A simple one-time registration is required that grants access to all the free archive content, across all of our specialist titles. To view or to register visit thorax.bmj.com. 